\title{
Opportunities and Threats to Learning: Lessons from a Pedagogical Workshop for Faculty at a Higher Education Institution
}

\author{
Proscovia Namubiru Ssentamu \\ Correpondence: Proscovia Namubiru Ssentamu, Senior Quality Assurance Officer and Lecturer, Uganda \\ Management Institute, Kampala, Uganda.
}

Received: July 11, 2013 Accepted: July 31, 2013 Online Published: October 21, 2013

doi:10.11114/jets.v2i1.248

URL: http://dx.doi.org/10.11114/jets.v2i1.248

\begin{abstract}
Faculty quality is a key variable in the quality of teaching and learning. However, although learning is the basis for teaching, the circumstances under which faculty learn largely remain unexplained. This paper focuses on the opportunities and threats to learning by faculty at Uganda Management Institute (UMI). The paper is based on a study of the evaluations completed by faculty at a pedagogical workshop organised to strengthen their teaching knowledge, skills and attitudes. A case study confirmatory research design was used to identify and analyze the opportunities and threats affecting learning based on the theories of constructivism, social constructivism and the principles of adult learning. Findings confirm that learning opportunities and threats are dependent on the degree of support from significant others, the content, methods and environment (Reigeluth \& Carr-Chellman, 2009; Aldridge \& Fraser, 1999; Seaman \& Fellenz, 1989). Faculty were more critical of the strengths and weaknesses of the facilitators, methods and environment than they were of the content and of themselves as learners. The evaluation of the former focused on the conduct and management of these constructs than on the constructs themselves. Limited self-reflection and criticism could be viewed from a wider Ugandan cultural perspective. Whereas the teaching of content could be evaluated differently, content itself is a context-independent variable, and therefore a stable phenomenon (Ssentamu, 2010). Based on the findings, higher education institutions could holistically focus on colleagues, facilitators, content, methods and environment as key constructs in enhancing faculty learning both at strategic and operational levels.
\end{abstract}

Keywords: pedagogy, adult learning, learning environment, evaluation, faculty, higher education.

\section{Introduction}

The vision of Uganda Management Institute (UMI) is to be a world-class Management Development Institute (MDI), and mission to excel in developing sustainable management capacity (UMI Strategic Plan, 2007). UMI provides management training, consultancy and research services in response to the demands of the public, private, and Non-Governmental Organizations (NGOs) sectors. It offers career development management courses at Certificate, Diploma, Postgraduate Diploma and Postgraduate Degree levels to a cross-section of participants including heads of government, private sectors and NGOs/Civil Society Sector, administrators, managers, central and local government staff, academics and researchers.

Currently, a range of programs at UMI seek to develop various competencies among participants in areas including governance, decentralization, public policy, public administration and management, NGO management, strategic leadership, disaster management, diversity management, fiscal policy, public financial management, public procurement, tax and revenue management, and urban governance and management (UMI Strategic Plan, 2007; UMI Prospectus, 2009). Developing these competences desired in all UMI programs, requires a combination of participatory methods such as practical hands-on exercises, case studies, class and small group discussions, role-plays, simulations and brief lecture sessions (UMI Prospectus, 2009). Consequently, faculty require training in relevant knowledge, skills and attitudes to be able to facilitate within the respective training programs.

With support of management, the Quality Assurance Unit (QAU) organized a five-day pedagogical training workshop for all UMI faculty. The workshop was aimed to enable participants reflect on their current teaching practices, improve their planning and implementation of teaching and learning, provide each other support and inspiration in their roles as facilitators of adult learning, and further develop these roles. Based on the 
participant-centred viewpoint, the workshop specifically sought to broaden participants' knowledge, skills and attitudes in their role as facilitators to be able to:

- appreciate the value of theories on teaching and learning, particularly adult learners.

- $\quad$ align the courses/course units based on the key curriculum elements.

- appreciate the centrality of aims, objectives and learning outcomes in teaching, learning and assessment.

- $\quad$ select from a wide range of teaching and assessment strategies to use for various class sizes.

- review examinations question items based on Blooms' Taxonomy of Educational Objectives.

- $\quad$ appreciate the importance of providing support to students.

Gibbs and Coffey (2000, cited in Gibbs \& Coffey, 2004) highlight the common goals of training of faculty as being the improvement of skills, development of conceptions of teaching and learning, ability to reflect and be self-improving, increase self-confidence or self-efficacy, and consequently cause change in students' learning. However, most training of faculty is oriented towards developing their teaching skills, especially in classroom practice (Gibbs and Coffey, 2004) at the expense of the development of other relevant skills, knowledge and attitudes that would enhance their teaching behaviors and outcomes.

HEIs in the UK, Norway and Sri Lanka are cited to have established formal initial training of university teachers, a trend on the rise in many other countries (Gibbs \& Coffey, 2004). Such training is noted to be substantial and sometimes linked to probation or tenure (Gibbs \& Coffey, op cit.). The scenario is slightly different in Uganda's HEIs in that most faculty embark on their teaching career with limited pedagogical knowledge, skill and experience; and hardly undergo any orientation or formal training during their teaching career. Pedagogical knowledge, skill and experience are of secondary importance upon appointment as faculty member; the core credential often considered being a qualification in the desired specialized area. The argument often is that such knowledge, skill and experience is acquired along the way. In addition, studies conducted about learning in HEIs have laid more emphasis on how students learn under the various circumstances, the rationale for and outcomes from such learning, and the importance of the learning environments in supporting learning (Abualrub, Karseth \& Stensaker, 2013; National Centre for Education Statistics, 2011; Higher Education Funding Council for England, 2010). Studies on faculty development have laid emphasis on the impact of training on faculty and rarely on the learning environment. For instance, a one-year longitudinal study of university teachers and students by Gibbs and Coffey (2004) focused on identifying changes in teachers' behavior and approaches to teaching and their students' approach to learning.

Given that few studies appreciate the circumstances that either promote or hinder the learning of faculty in HEIs, the aim of the current study was to explore such circumstances in a pedagogical workshop context. Specifically, the study sought answers to the following three research questions:

- What opportunities support the learning of faculty in a pedagogical workshop context?

- What threats hinder the learning of faculty in a pedagogical workshop context?

- What are the implications of the identified opportunities and threats to HEIs?

\subsection{Theoretical and Conceptual Underpinnings}

This study is based on the theories of constructivism, social constructivism and the principles of adult learning. In the constructivist paradigm the focus is on the participant [learner] rather than the facilitator [teacher], underlying the importance of the learner, environment and learning process. According to Thanasoulas (n.d.) this process is inescapably affected by the context, the beliefs and attitudes of the learner. The learner interacts with the environment, which enables him/her to understand its features and characteristics. In the current study therefore, the learning environment provided in the pedagogical workshop was assumed to influence the way the participants construct meaning in the teaching and learning process. Effective teaching and learning requires active construction of meaning by participants. This implies that participants can construct meaning under several circumstances such as through sharing of knowledge and skills with others, manipulation of concrete materials to practice what they have learnt, sensing progress in what they are learning, and perceiving linkages between what they know and what they are learning. In such a learning environment, the adult learner is respected and learning takes place in an open and non-threatening environment.

Respect for the adult learner in such an environment underscores the importance of the knowledge, beliefs and skills an individual brings to bear on learning as advanced in the theory of constructivism. The same theory also advocates the empowerment of adult learners to make informed choices about what to accept [and what to reject], 
and how to fit it into their existing schemata (Merrill, 2009; Thanasoulas, n.d: 6-7), which motivates learning. Motivation, beliefs and attitudes to perform in an effective way is significantly increased and learning is more stable and likely to survive much longer when learners know that they will have an opportunity to demonstrate their newly acquired skill to significant others at their workplaces (Merrill, 2009). Significant others are key in supporting individual learners in the learning process. According to the theory of social constructivism, learning is socially mediated and situated. It is a social process where an amalgam of interpersonal and intrapersonal means are used in conversation with one's self and in joint action with others (Holman, 2000: 206).

In addition to the theories of constructivism and social constructivism, the study found the principles of adult learning important in further illuminating how adults learn. However, this study limited itself to five basic principles propounded by Knowles (in Lieb, 1991). According to Knowles, adults:

- $\quad$ are autonomous and self-directed; therefore the facilitator must actively involve the adult participant in the learning process.

- have accumulated a foundation of life experiences and knowledge that may be related to their work, family or previous education; therefore they connect learning to experience.

- $\quad$ are goal-directed; therefore they need to be informed early in the training what goals they have to work towards.

- $\quad$ are relevancy-oriented; therefore what they learn must be applicable to their work or responsibilities.

- $\quad$ are practical; therefore training must be useful to them in their work.

In addition, Goodlad (in Sweeny, 2008) suggests that adults prefer a learning environment which:

- $\quad$ is practical and problem-centered,

- $\quad$ promotes their positive self esteem,

- integrates new ideas with existing knowledge,

- shows respect for the individual learner,

- capitalizes on their experience, and

- $\quad$ allows choice and self-direction.

Therefore, adults prefer learning situations that are practical-oriented and flexible, content that is relevant to their work and based on experience sharing, tapping on their autonomy and positive self-esteem. Although these principles are easily accommodated in the theory of constructivism, the significant other(s) advocated in the theory of social constructivism is less focused on.

The theories of constructivism and social constructivism, and the principles of adult learning enabled the current study interrogate what the participants focused on and why they focused on particular aspects in evaluating the pedagogical workshop. The theories and principles of adult learning focus on the process rather than the content of learning, and target adult learners, since these have a repertoire of knowledge and experiences to draw upon. The assumption is that the more the learning opportunities are aligned with the two theories and the principles of adult learning, the better the quality of learning at individual and organizational level.

In this study, pedagogy was defined as the art and science of teaching in order to facilitate learning. Pedagogy is a commonly acceptable term in higher education, even when its philosophy is based on basic education, particularly the art and science of teaching children. Faculty should have the relevant pedagogical knowledge, skills and attitudes to be able to facilitate learning. The workshop training content may include but may not be limited to either practically orienting or reminding Faculty about the following thematic areas:-

- learner-centered theories.

- $\quad$ course and module alignment.

- the centrality of aims, objectives and learning outcomes in teaching, learning and assessment.

- teaching strategies for various class sizes.

- $\quad$ assessment and examination principles and strategies.

- $\quad$ student support.

The assumption is that when Faculty acquire and further develop the above knowledge, skills and positive attitudes, they are able to conduct student-centered teaching in their classes, which was beyond the scope of the current study. 
Adult learning or andragogy is the art and science of helping adults learn (Knowles in Lieb, 1991). Because of its emphasis on learners, andragogy is currently associated with learner-centered education, and because of its emphasis on meaning-making, it supports the theory of constructivism. According to Knowles, andragogy is process-based rather than content-based. Andragogy is vital because it promotes work or career-related learning where individual experience is paramount. However, despite the use of the term pedagogy, the practices in HEIs should be andragogical in practice.

The need for organizational learning has grown tremendously in HEIs in recent years. Organizational learning is concerned with the development of new knowledge or insights that have the potential to influence behavior (Mabey \& Salaman, in Armstrong, 2007). It refers broadly to an organization's acquisition of understanding, know-how, techniques and practices of any kind and by any means (Argyris \& Schon in Armstrong, op cit.: 540). Effective learning in organizations takes cognizance of the support and commitment of the managers, a shared institutional vision and culture of growth, and a conducive learning and innovative environment. According to Senge, learning organizations are:

-.organizations where people continually expand their capacity to create the results they truly desire, where new and expansive patterns of thinking are nurtured, where collective aspiration is set free, and where people are continually learning to see the whole together (cited in Smith, 2001:2).

Abualrub et al., (2013) traced the early attempts to analyse the learning environment within school classes back to the 1930s. Citing a study by Aldridge and Fraser (1999) the learning environment which determines learners' behaviors and outcomes is typified by interactions between the environment and personal characteristics (Lewin, 1936), situational variables in the individual's environment (Murray, 1938), interactions of personal needs and expectations of learners within their classroom environment (Getzels \& Thelen, 1960), correspondence between the environment and learner's personal needs, i.e. Person-Environment Congruence (Stern, 1970), interactions between various variables, i.e. age, ability and motivation of the learner, the quantity and quality of instruction, home, classroom, peer groups and media environments (Walberg, 1979), and the social climate (Moos, 1979). According to Abualrub et al., (2013) the above studies expanded the scope of research into the learning environment from focusing on possible relationships between individuals' behaviors and their surrounding environments to identification of the variables of learning environments and how they affect learners' behavior; and from the in-class and instruction environment to the surrounding environmental co-determinants in addition to the learners' backgrounds, personal experience and affiliated groups.

Learning environments have been defined variously in the literature. For example, learning environments have been defined as the conditions that are created to improve learning experience; atmosphere, ambience, tone, or climate that pervades a particular setting; and material and social conditions that provide learners with opportunities to learn (Granić, 2009; Aldridge et al., 2004; Illeris, 2004; cited in Abualrub et al., 2013). By exploring the key variables that either promote or deter faculty from constructing meaning in a pedagogical workshop, it was hoped that the current study would further contribute to the conceptualization of adult learning environments. Learning environment in the current study was perceived as a pedagogical setting that has a very close and direct relation to the teaching and learning experience (Abualrub et al., 2013).

\section{Methodology}

This study employed a confirmatory case study research design using the qualitative method. The aim was to enable the researcher confirm certain constructs influencing learning suggested in the literature (Reigeluth \& Carr-Chellman, 2009, Seaman \& Fellenz, 1989).

This strategy enabled the identification, categorization and description of participants' views on key factors affecting learning in a workshop training mode. Participants' views were already pre-coded on the evaluation form, however, the study identified five sub-categories from the already pre-coded data. Following Strauss and Corbin's (1990) approach, open coding was used to identify categories and their relationships by examining the data word-by-word and phrase-by-phrase. After open coding, axial coding was used to make explicit connections between categories and their relationships. This was done by referring to relevant literature and theory. Lastly, selective coding was used to identify the core categories and relating other categories to the core categories. Coding helped the researcher to think critically about the data and relate them in complex ways. Care was taken to allow categories to emerge naturally, since this was one of the bases for ascertaining the validity of the findings.

Data was analyzed using the content analysis technique, with the identified core and sub-categories providing the guiding framework. Participants' written comments were read to identify patterns and relationships in relation to the core and sub-categories that had emerged during data coding. Where necessary, analysis was enhanced by 
quoting respondents' notes. Codes were used with the aim of keeping the identity of the participants. In presenting, analyzing, and interpreting the data, the experience of the researcher in teacher education over the years seemed to be a limiting factor. Trying as much as possible to focus on what was written on the evaluation forms, and reviewing literature on the core categories emerging from the data controlled this limitation.

\subsection{The Evaluation Form}

Out of the 60 staff, between 15-30 participants attended daily and completed evaluation forms. By the end of the workshop, 50 forms were collected; and these formed the source of data for this study. On the forms, participants [faculty] were asked to list strengths, weaknesses, key issues learnt; and suggestions for improvement. Participants were asked not to include their names on the evaluation forms, so that they could freely express their views under each of the above categories.

This study explored two aspects on the evaluation form, i.e. participants' views on the strengths and weaknesses of the pedagogical workshop.

\section{Findings and Discussion}

The findings of the study are presented, analyzed and discussed under five major categories identified during data analysis, i.e. participants, facilitators, content and materials, methods, and environment.

\subsection{Category One: The Participants}

Most participants perceived workshop strengths from a learner point of view. Such participants located themselves as well as others in a learning web, and the learning process as a social process. The following excerpts from various evaluation forms describe the perceptions of some participants:

\section{$\mathrm{A}[1]$ Effective participation of members.}

C[1] Good participation of the participants.

$\mathrm{D}[1]$ Quite interactive.

$\mathrm{K}[1]$ Interactive discussions.

L[1] Group presentations.

G[1] Involvement of participants in discussions.

AN[1] Free interaction.

$\mathrm{P}[1]$ Openness.

For this category of participants learning is a social activity, whereby in order for effective learning to take place, learners freely and actively participate and interact in group work, sharing and discussions. This is because effective learning depends on group presence and support. According to Abualrub et al., (2013) a learning environment based on social actions and conditions is considered from a network perspective, since it allows learners to find and belong to groups that have values and interests similar to their individual values and interests, where they can share and exchange experiences and knowledge with others, and find security and protection of identity in new study settings. Social learning networks have been found to have a positive impact on students' learning outcome (Sawir et al., 2008; Trowler, 2010; Krause, 2006 in Abualrub et al., 2013), this precondition is not different for faculty engaged in a learning activity.

On the other hand, participants' most commonly mentioned workshop weakness was poor time management, most especially on the part of participants [cited by six participants], followed by the unnecessary in and out movements by participants [cited by four participants], persistent phone calls which disrupted others [cited by four participants], some participants attending only the morning session and others not attending at all [cited by two participants].

In the workshop mode of training, non-residential workshops present with them numerous problems ranging from poor time management, constant in-and-out movements, partial participation and attendance, to non-attendance. Most participants who highlighted participation as a major workshop strength were also perturbed by the disruptive behavior among their colleagues. In addition, some participants noted other forms of learning disruption as illustrated in the excerpts below:

\section{$\mathrm{K}[2]$ Derailing of some topic coverage by irrelevant questions.}

AN[2] Failing to build a consensus on some issues.

Facilitators play a key role in refocusing the workshop, trouble-shooting and building consensus among participants. Failure to do this leads to a learning disruption. This explains why adult learners are perturbed by 
facilitators who do not stick to the session's theme and cannot lead a group to compromise on conflicting arguments.

The strengths of adult learners leans more on group dynamics in a training workshop. In addition, participants' weaknesses during the learning process tend to focus towards other colleagues than towards themselves. This further strengthens the role of significant others in learning, especially when such learning is not competitive. When the significant others are supportive of their learning, learning takes place, and when they are disruptive, the learning process is disrupted. The potential question that such learners would be asking the significant others is: 'why don't you settle down and learn with us?' Reigeluth and Carr-Chellman (2009:24) suggest other instructional conditions related to the learner including, i.e. the nature of the learner, prior knowledge, learning styles and strategies, motivations, and interests. However, these aspects did not emerge in the findings of the current study. In addition, learning deterrence could also point to lack of the culture of self-appraisal and reflection among some adult learners regarding their own learning strengths and weaknesses.

\subsection{Category Two: The Facilitators}

The facilitators were a team of teacher educators who had conducted similar trainings in other HEIs. The team was selected on the basis that participants' learning is influenced by the expertise and acumen of facilitators in a training workshop. This category emerging from the research findings illustrates that the participants-facilitators interaction is crucial in either creating or threatening a learning opportunity. Findings show that participants were more critical about facilitators' strengths and weaknesses than they were about their own. The expressions used by participants to describe facilitators' strengths have been sub-dived into three sub-categories as illustrated below:

\subsubsection{Sub-category One: Expertise}

A[2] Highly knowledgeable, skilled, and experienced consultants.

$\mathrm{B}$ [2] Mastery of the subject matters.

E[2] Facilitators explained the facts well.

$\mathrm{G}[2]$ Relevant examples.

K[2] Student-centered techniques.

$\mathrm{M}[2]$ Interactive discussions.

$\mathrm{N}[2]$ Focused presentations within given time frames.

$\mathrm{P}[2] \quad$ Facilitators were consistent and focused on the work.

$\mathrm{Q}[2]$ Organized facilitators.

$\mathrm{R}[2]$ Clarity on part of the presenters.

$\mathrm{T}[2]$ Quality of PP [Power Point] presentations.

$\mathrm{U}[2]$ Keeping participants glued to the presentation.

$\mathrm{X}[2]$ Explaining issues that were unclear or misunderstood culminating from the presentations.

W[2] Presentation styles.

GB[2] Various lecturing styles.

JA[2] Clearly presented material.

SS[2] Trainers remained active and displayed good knowledge of the content they were delivering.

$\mathrm{HB}[2]$ The presenters were up to the task.

In this sub-category, facilitators' strengths perceived from the participants' viewpoint focused on knowledge of the content and use of a variety of delivery strategies, most especially participatory methods.

3.2.2 Sub-category Two: Teamwork

$\mathrm{E}[2]$ Exchange between the facilitators.

$\mathrm{G}[2]$ The training has been interactive and there is good team teaching.

$\mathrm{HC}[2]$ Effective team teaching.

JD[2] Co-lecturing by facilitators.

$\mathrm{P}[2] \quad$ Team dynamics. 


\section{WA[2] Team presentation.}

Under the sub-category 'teamwork', facilitators were appraised for team teaching, which was a result of team planning. This clearly brings out the social dimension in the adult learning process. Good teaching teams are likely to build good learning teams. The participants [faculty] are also likely to emulate such teamwork in their own classrooms.

\subsubsection{Sub-category Three: Facilitator Personality}

\section{D[2] Facilitators were confident.}

F[2] Lively lectures.

G[2] Free interaction.

$\mathrm{Y}[2]$ Openness.

$\mathrm{AB}[2]$ The facilitators were confident; perhaps they had discovered the expectation of the participants.

AA[2] Thumbs up for the guest speakers.

Facilitator personality in this case was considered in terms of group personality, since team teaching was practiced as a workshop pedagogical strategy. Facilitators were described as confident, lively and open, which relaxed the teaching and learning environment and gave the workshop a good tempo. The knowledge, skills and personalities of the facilitators are key ingredients in enhancing learning.

From the participants' perspectives, facilitators' weaknesses included among others the failure to build a consensus on some issues and to keep discussions in focus, as evident in the following excepts:

F[2] Participants were left to react at will and at times in confrontation towards others with different views.

$\mathrm{K}[2] \quad$ Derailing of some topic coverage by irrelevant questions.

AN[2] Failing to build a consensus on some issues.

Other weaknesses included poor time management leading to rush in some presentations, excessive irrelevant conclusions, and presentation handouts not being distributed immediately.

Most of the weaknesses cited above relate to the management of the training in general and the facilitation process in particular. In addition to expertise and personality, a facilitator is a manager of the teaching and learning process. Among the workshop management-related issues include class control and management, moderation of discussions, time management, and management of handouts and other reading workshop materials, which are of keen interest to an adult learner.

\subsection{Category 3: Content and Materials}

Content is the nature of what is to be learned, defined comprehensively to include knowledge, skills, attitudes and values (Reigeluth \& Carr-Chellman, 2009:24). The team of facilitators planned the workshop content based on their experience in facilitating similar workshops in other HEIs. Their reasoning was that similar pedagogical issues cut across many HEIs in Uganda. The themes handled included the theories on teaching and learning; learner-centered education; course planning and writing; course alignment; learning goals, aims, objectives and outcomes; the phases of teaching; inquiry/problem solving; participatory methods for large classes including field work, project work and portfolio; using IT in teaching and learning; assessment strategies; being a course leader; and students' expectations and support. However, effort was made to contextualize the content to UMI.

Similar to participants' rating of the facilitators, their rating of the content and materials was more critical than their rating of themselves as learners. Participants evaluated the content and materials as 'very relevant', 'rich', 'broad', 'very informative', 'varied', 'interesting', 'applicable', 'well-sequenced' and 'new'. Some participants observed that the reference materials were timely distributed.

To some participants, the workshop content was a refresher of either what they had learnt earlier during their training or where currently facilitating in the Trainer of Trainers' Module at UMI. However, majority of participants had a first time exposure to such content, although they had been facilitating on various public administration and management-related training programs at UMI. According to Bruner (cited in Thanasoulas, n.d.) learning is a social process whereby;

-.students [participants] construct new concepts based on current knowledge. The student [participant] selects information, constructs hypotheses, and makes decisions, with the aim of integrating new experiences into his existing mental constructs. It is cognitive structures that provide meaning and organization to experiences and allow learners to transcend the boundaries of the information given 
(p.5-6).

Bruner's social process is related to the principles of constructivism which include:

- instruction must be commensurate with the experiences that make the student willing and able to learn (readiness).

- instruction must be structured so that it can be easily understood by the student (spiral organization).

- instruction should be designed to facilitate extrapolation (going beyond the information given).

In relation to the current study, workshop content and materials were those that were located within the participants' environment, were relevant and well-sequenced beginning with the theories underpinning teaching and learning and drawing on these in more practical and familiar ways. Such content stimulated transference of learning, which is among the four critical elements that must be addressed to ensure that learning takes place. According to Lieb (1991), transference, which is a result of training, is the ability to use the taught content [and skills] in new situations. Lieb further notes that transference is likely to occur when participants can associate the new information with something that they already know, when the information is similar to material that participants already know, that is, it revisits a logical framework or pattern; when participant's degree of original learning is high; and when the information learned contains elements that are extremely beneficial (critical) on the job.

There were not many weaknesses noted by participants with regard to content and materials except that the content was too much for so short a time, which limited exhaustive discussions. Too much content is also detrimental to pedagogical practical skills development. Other than time, a few participants observed that the handouts were not numbered which affected quick reference to the materials referred to during the workshop, and failure to distribute power point presentations during the sessions.

Participants' evaluation of content and materials could be related to the thinking that content is a context-independent variable, since it is concerned with factual knowledge (Ssentamu, 2010). For instance, content on Bloom's Taxonomy of educational objectives can be perceived as a constant, while teaching Bloom's Taxonomy could be perceived differently. Therefore, it is easy for workshop participants to critique the practical, the personal, the social orientations (Reddy, Menkveld \& Bitzer, 2008) as well as the management of the workshop methods, than the content. Context-dependent variables are factors that are perceived subjectively because they demand the powers of critical reflection and practical inquiry (Ssentamu, 2010). Therefore, one of the major roles of a facilitator is not only to select relevant content and materials, but also to place these in the immediate context of the learner. The more familiar the content and materials are, the more the learners construct meanings from them, using the familiar as the basis for learning.

\subsection{Category 4: Facilitation Methods}

In this study, facilitation methods are the instructional processes with defined set of procedures such as the interactive lecture, demonstration, and case study used during the teaching and learning process (Knott \& Mutungi, 1985). The workshop assumed that the participants were experienced in their various fields; therefore would draw on their rich repertoire of experience in a participatory manner. The nature of participants, the workshop aim, learning outcomes, content and duration were key determinants in selecting the facilitation methods. The assumption was that blended methods would achieve the workshop objectives (Armstrong, 2007). The workshop as a learning mode had the advantage of ensuring that all participants learnt the same way and at the same time.

Participants' perception of the workshop strengths regarding methods and techniques focused on the participant-facilitator interactions, participant involvement, use of participatory methods in the sessions, openness, focused presentations and clear procedure as illustrated in the following excerpts:

\author{
'The training has been interactive and there is \\ good team teaching.' \\ 'Co-lecturing by facilitators.' \\ 'The training was very interactive.' \\ 'Orderly presentations.' \\ 'Presentation styles.' \\ 'Various facilitation styles.' \\ 'Effective participation of members.' \\ 'Delivery methods very appropriate.' \\ 'Participatory methods of teaching.' \\ 'Student-centered centered techniques.'
}

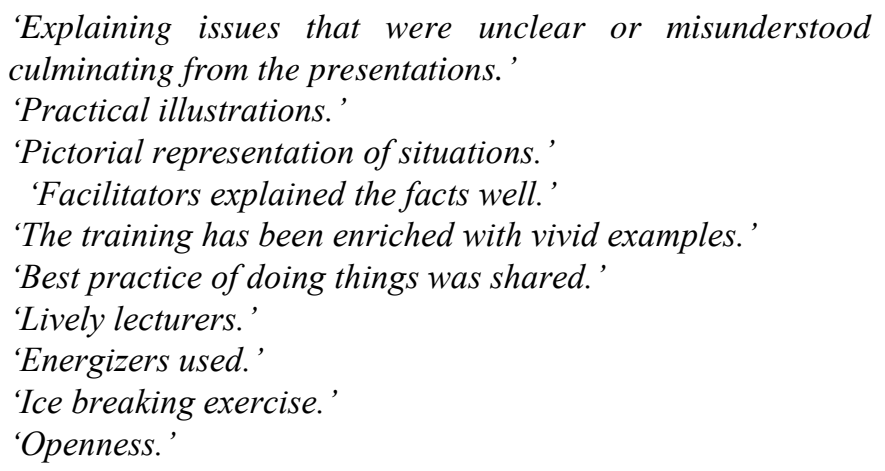




\section{'Group presentations.' \\ 'Group discussion.'}

The methods used in the workshop were in line with the participant-oriented strategies and the principles underpinning adult learning. In addition, the workshop methods and techniques leaned towards the theories of constructivism and social constructivism with more focus on the participant [learner] than the facilitator [teacher]. According to Thanasoulas (n.d.) in constructivist thinking, learning is inescapably affected by the context, beliefs and attitudes of the learner. There was attempt by the facilitators to embed the workshop content and methodology in a social context to allow participants take part in meaningful activities that induce them to reflect on and apply what they were learning. Such opportunity according to Thanasoulas (n.d.) promotes the formation of a community of learners [as well as practitioners] who construct their knowledge together. Both the theories of constructivism and social constructivism focus on experience and active engagement of the learner(s) in the learning process.

The major weakness considered by the participants was the limited time to engage in group discussions as well as the encouragement of irrelevant questions. The weakness pointed out was not methodological, rather it related to the management of the various methods used by the facilitators. Merrill (2009) suggests the following instructional strategy scale as promoting successive improvement in the performance on complex, real-world tasks in several levels:

\section{Levels}

Level One

Level Two

Level Three

\section{Instructional Strategy}

Information, consistent demonstration

Corrective feedback to information, demonstration, consistent application

Corrective feedback to information, demonstration, consistent application, using a task-centered instructional strategy, activation

Level Four

Personal use and going public integration (Merrill, 2009:55).

The above scale gives a structure of a logical presentation, and basically details the traditional structure we all know, i.e. simple to complex, known to unknown, and theory to practice. However, notable is that that the higher the level of the instructional strategy, the more constructive and social learning becomes, and the more practical the instructional strategy turns out to be. When adult learners do not see a logical sequencing of what they are learning, they will not value such learning. In addition, learning will not be cherished when learners do not see the relevancy and practicality of what they are learning in solving theirs and others' problems in work situations.

The current study registered most evaluations regarding workshop strengths and weaknesses in the methods category in comparison to evaluations of the participants themselves, the facilitators, content and the environment. This underscores the importance of the instructional strategies used in a training workshop. The facilitation methods will determine the level of interaction, participation and transference of learning.

\subsection{Category 5: Environment}

The situation in which learning takes place influences how adults learn (Seaman \& Fellenz, 1989). The scope of the learning environment includes among others human resources, material resources and organizational arrangements, and attitudes of administrative staff towards adult learning (Reigeluth \& Carr-Chellman, 2009; Seaman \& Fellenz, 1989). In this study, similar factors were established as either creating an opportunity or threat to learning. The major internal workshop environmental strengths highlighted under this category were a conducive teaching and learning environment and time management.

Participants also noted some external co-determinants as either facilitating or hindering learning, including logistical support in form of meals, allowance for outreach staff, a certificate at the end of the workshop; the inspiring remarks made at the conclusion of the workshop by the workshop coordinator, participants' representative and Director General; and the timing of the workshop during recess to enable participants attend. This finding is supported by studies that identified managerial and administrative structures and behavior, collegial and campus climate; and services provided to learners as organizational conditions that support learning (Del Favero, 2002; Pascarella \& Terenzini in Abualrub, et al., 2013). Further, such a learning environment can be perceived as a response to wider quality challenges including massification, internationalization and emergency of the knowledge economy, which as alluded to by Abualrub, et al., (2013) necessitate life long learning. Lieb (1991) provides an expanded version of the sources of motivation in relation to adult learners. These have been interpreted in the current study to include: 
- $\quad$ social relationships - does the participant perceive the workshop as an avenue for making new friends or meeting old ones?

- external expectations - does the participant attend the workshop to comply with instructions or recommendations from authority?

- $\quad$ social welfare - does the participant perceive the workshop as an avenue to improve his/her ability to serve the institute and community?

- personal advancement - does the participant perceive the workshop as an avenue to achieve higher job status, secure professional advancement, or stay abreast of competitors?

- escape/stimulation - does the participant perceive the workshop as an avenue to relieve boredom, or provide a break in the routine of home or work? and

- cognitive interest - does the participant perceive the workshop as an avenue to learn for the sake of learning, seek knowledge for its own sake, and to satisfy an inquiring mind?

In the current study, all the above sources of motivation seemed to come into play, but in combinations and variations, depending on the individual participants.

A number of weaknesses were also noted including poor time management by participants and some facilitators; too much content visa-â-vie the available time, difficulty in locating the reading materials referred to in the folders, since these were not numbered; distractive movements and phone calls, technological disruptions by the LCD, non- or partial-attendance by some members, and failure of most members of the top management team to attend. Here again, Lieb (op cit.) highlights barriers to motivation among adult learners to include lack of time, money, confidence, interest, lack of information about opportunities to learn, scheduling problems, 'red tape,' and problems with childcare and transportation.

A conducive learning environment, both internal and external is a key motivating factor in enhancing quality learning. An environment characterized by openness, challenge, liveliness, positive rewards, peer critique, care and support, quality relations, mutual respect and immediate feedback will motivate learning. These factors endorse some of the principles of adult learning cited by Knowles (in Lieb, 1991) and Goodlad (in Sweeny, 2005). Further, a harmonious relationship between academic and administrative organs is crucial for the enhancement of faculty capacity building programs whose ultimate goal could lead to individual but also to institutional development.

\section{Conclusion}

Findings confirm that workshop participants, facilitators, content, methods and environment either promote or deter learning among adult learners. This is in agreement with Merrills' (2009:26) observation that content, learner, learning environment and instructional development constraints are key instructional conditions. In addition, this study supports the theory advanced by Walberg, (1979 in Aldridge \& Fraser, 1999) that learning is a function of a number of variables. In his study, the learners' age, ability and motivation, the quantity and quality of instruction, home, classroom, peer groups and media environments were key variables. In the current study, workshop participants, facilitators, content, methods and environment emerged key determinants of adult learner behavior and outcomes. Support from management, logistics, and the timing of the workshop emerged co-determinants. Apart from Moos, (1979) who initiated a classroom environment scale, other classic studies in the field did not rank the above variables in the order of importance (Lewin, 1936; Murray, 1938; Getzels \& Thelen, 1960; Stern, 1970; Walberg, 1979 in Aldridge \& Fraser, 1999). However, it is evident that the interrelationship of these variables according to the classic studies and according to Seaman and Fellenz, (1989) magnifies their importance in the learning process.

Significant in adult learning is the degree of support from other learners or participants, giving learning a social dimension. Further, participants are more critical about the strengths and weaknesses of facilitators, methods and environment than they are of the content and of themselves as individual learners. Being non-self critical and non-reflective could be considered from a wider cultural perspective, where much of the Ugandan society has not developed the culture of self-criticism and reflection. However, the evaluation of facilitators, methods and environment focuses on the conduct and management of these constructs than on the constructs themselves. Whereas the teaching of content could be evaluated differently, content itself is a context-independent variable, a more stable phenomenon than the other constructs (Ssentamu, 2010). Context-dependent variables are those factors that are perceived subjectively, i.e. facilitators, other participants, management of the workshop methods, and environment because they demand the powers of critical reflection and practical inquiry (Ssentamu, op cit.). For instance, content on Bloom's Taxonomy of educational objectives can be perceived as a constant, while its 
teaching could be perceived differently. Therefore, it is easy for workshop participants to critique the practical, the personal and the social orientations (Reddy et al., 2008), as well as the ability of the facilitators to select and use appropriate methods, than to critique the actual methods used and the content.

Despite the differences among the five constructs, their inter-relationship in training is crucial based on the principles of andragogy and the theories of constructivism and social constructivism. For effective learning to take place, all the constructs must be inextricably harmonized during the pre-, actual- and post-facilitation phases.

\section{Implications}

The implications of the study to HEIs are multifaceted to include the following:

- based on the theory of constructivism and the principles of adult learning, colleagues, facilitators, content, methods and environment are key constructs in enhancing organizational learning. Therefore, HEIs need to holistically focus on these constructs at strategic and operational levels.

- when faculty appreciate the benefits from a training, they are likely to cascade the developed knowledge, skills and attitudes to the beneficiaries, i.e. their students; such benefits will be long lasting.

- knowledge, skills and attitudes learnt during such workshops should be carefully selected since these have a direct bearing on the end users, i.e. the students. In order to improve students' learning processes and outcomes, training of faculty should primarily be oriented towards improving student learning, rather than towards improving teaching as performance (Gibbs \& Coffey, 2004). According to Gibbs and Coffey (ibid), training of faculty should aim at changing them so that they are in position to support and use student-centered learning approaches in their own classrooms.

- organizational learning is not a one-off experience, since changes occur within and beyond HEIs almost on a daily basis. HEIs should embrace individual and group lifelong learning strategies for faculty. There are various forms of support that HEIs could provide faculty including discussion of student feedback and departmental mentors (Gibbs \& Coffey, 2004).

- a harmonious relationship between academic and administrative organs is crucial for the enhancement of staff development programs whose ultimate goal could lead to individual and institutional development.

- for better impact, training of faculty in teaching in HEIs should take place at the beginning of their teaching career in order to mitigate against the development of what Gibbs \& Coffey (2004: 89-90 ) call negative values and a teacher focus early in a one's career. This would necessitate that new faculty communicate their learning needs to the administrators so that these are included in the human resource planning process.

- organizational constraints are barriers to the growth and development of learning organizations, and efforts should be made to control them.

- further research could be conducted to establish the strength and importance of each variable in promoting adult learners.

\section{Acknowledgement}

I acknowledge the management and faculty of Uganda Management Institute for giving me the opportunity to coordinate and facilitate the pedagogical workshop.

\section{References}

Abualrub, L., Karseth, B., \& Stensaker, B. (2013). The various understandings of learning environment in higher education and its quality implications. In Quality in Higher Education, (Vol. 19, No. 1, pp. 73-110). http://dx.doi.org/10.1080/13538322.2013.772464

Aldridge, J., \& Fraser, B. (1999). A cross-cultural study of classroom learning environments in Australia and Taiwan. In Learning Environment Research, 3(2), 101-134. http://dx.doi.org/10.1023/A:1026599727439

Armstrong, M. (2007 reprint). A handbook of human resource management practice, $10^{\text {th }}$ Education. London: Kogan Page.

Gibbs, G., \& Coffey, M. (2004). The impact of training of university teachers on their teaching skills, their approach to teaching and the approach to learning of their students. In Active Learning in Higher Education, 5(87), 87-100. Retrieved from alh.sagepub.com at University of Sydney on July 18, 2013

Hofmann, S. (2005). 10 years on: Lessons learned from the Institutional Evaluation Program, A European University Association report with support of HRK-German Rectors' Conference and the Accreditation, 
Certification and Quality Assurance Institute.

Holman, D. (2000). Contemporary models of management in education. In Management Learning, 31(2), 197-217. Retrieved from mlq.sagepub.com at University of Sydney on July 18, 2013

Inter-University Council for East Africa. (2008). A road map to quality: A handbook for quality assurance in higher education, Vol.1: Guidelines for self assessment at program level.

Knott, M., \& Mutungi, P. (1985). Methods of teaching and learning. In B. Matiru, A. Mwangi, \& R. Schlette (Eds.), Teach your best: A handbook for University Lecturers, Institute for Socio-cultural Studies, University of Kassel, Germany.

Knowles, M. (1990). The adult learner. A neglected species, $\left(4^{\text {th }}\right.$ ed.). Houston: Gulf Publishing.

Lieb, S. (1991). Principles of adult learning. Retrieved from wcwpds.wisc.edu/mandatedreporter/adult_learning.pdf on the $3^{\text {rd }}$ of January, 2011.

McCarthy, M., \& Higgs, B. (2005). The scholarship of teaching and its implications for practice. In G. O'Neill, S. Moore, \& B. McMullin (Eds.) Emerging issues in the practice of University learning and teaching. Dublin: All Ireland Society for Higher Education.

Merrill, M. D. (2009). First principles of instruction. In C. M. Reigeluth \& A. A. Carr-Chellman (Eds.), Instructional-design theories and models: Building a common knowledge base. (Vol. 3. pp. 41-56). New York: Routledge, Taylor and Francis Publishers.

Reddy, C., Menkveld, H., \& Bitzer, E. (2008). The practicum in pre-service teacher education: A survey of institutional practices. In Southern African Review of Education, A Journal of Comparative and History of Education, 14(1-2), 143-163.

Reigeluth, C. M., \& Carr-Chellman, A. A. (Eds.) (2009). Instructional-design theories and models: Building a common knowledge base. (Vol. 3.). New York: Routledge, Taylor and Francis Publishers.

Seaman, D., \& Fellenz, R. A. (1989). Effective strategies for teaching adults. New York: Maxwell Macmillan International Publishing Group.

Smith, K. M. (2002). Peter Senge and the learning organization. Retrieved from http://www.infed.org/thinkers/senge.htm on the 27th of Feb., 2011

Ssentamu, N. P. (2010). Teaching practicum supervisors' identity and student assessment on the practicum: An assorted mind-set? In African Education Review, 7(2), 305-322.

Ssentamu, N. P., Ezati, B. A., \& Ocheng, M. T. K. (2010). Does assessment feedback during practicum facilitate students to improve on their practice? Lessons from Makerere University.' In Malawi Journal of Education and Development, 1, 1-14.

Strauss, A., \& Corbin, J. (1990). Basics of qualitative research: Grounded theory procedures and techniques. Newbury Part, CA: Sage.

Sweeny, B. (2008). The principles of adult learning: based on the ideas of John Goodlad; Best practice resources. Retrieved from www.businessmentorcenter.com/AdultLrng.php on the $3^{\text {rd }}$ of January, 2011.

Thanasoulas, D. (n.d.). Constructivist learning. Retrieved from http://www3.telus.net/linguisticsissues/constructivist.html on the 3rd of January, 2011.

UMI Prospectus. (2009). 2010/2011. Kampala: New Vision.

UMI. (2007). Strategic plan 2008-2013: Developing sustainable management capacity. Kampala, New Vision.

Higher Education Funding Council for England. (2010). Annual report and accounts 2009-10. London, HEFCE. Available at: http://www.hefce.ac.uk/media/hefce/content/about/howweoperate/annualaccounts/HEFCEac-counts0910.pdf (accessed $11^{\text {th }}$ July, 2013).

National Centre for Education Statistics. (2011). The conditions of education, Washington DC, National Centre for Education Statistics. Available at: http://nces.ed.gov/programs/coe/ (accessed 11 ${ }^{\text {th }}$ July, 2013).

\section{(cc) $E Y$}

This work is licensed under a Creative Commons Attribution 3.0 License. 